\title{
IGNITION AND PROPAGATION PROPERTIES OF COAL DUST - AIR - METHANE HYBRID MIXTURES
}

\author{
Maria PRODAN, ${ }^{\mathrm{a},{ }^{*}}$ Emilian GHICIOI, ${ }^{\mathrm{a}}$ Adrian JURCA ${ }^{\mathrm{a}}$ and Dumitru OANCEA ${ }^{\mathrm{b}, * *}$ \\ ${ }^{a}$ National Institute for Research and Development in Mine Safety and Protection to Explosion - INSEMEX, \\ 33-34 G-ral Vasile Milea str., Petrosani, Roumania \\ ${ }^{\mathrm{b}}$ Department of Physical Chemistry, University of Bucharest, 4-12 Bd. Elisabeta, 030018 Bucharest, Roumania
}

Received August 6, 2020

The presence of a flammable gas in a combustible dust cloud significantly modifies its explosivity parameters. Thus, a hybrid mixture can become flammable even when both the dust-air and gasair binary mixtures are under the corresponding lower explosion limits. The pressure-time histories of hybrid mixtures formed by coal dust, methane and air at different concentrations, at 1 bar initial pressure and normal temperature, were studied using the standard $20 \mathrm{~L}$ spherical explosion vessel and $5 \mathrm{~kJ}$ chemical igniters or $10 \mathrm{~J}$ permanent sparks. From the early stages of the pressure-time history, when the pressure increase is equal to or less than the initial pressure, the normal burning velocities were evaluated and discussed.

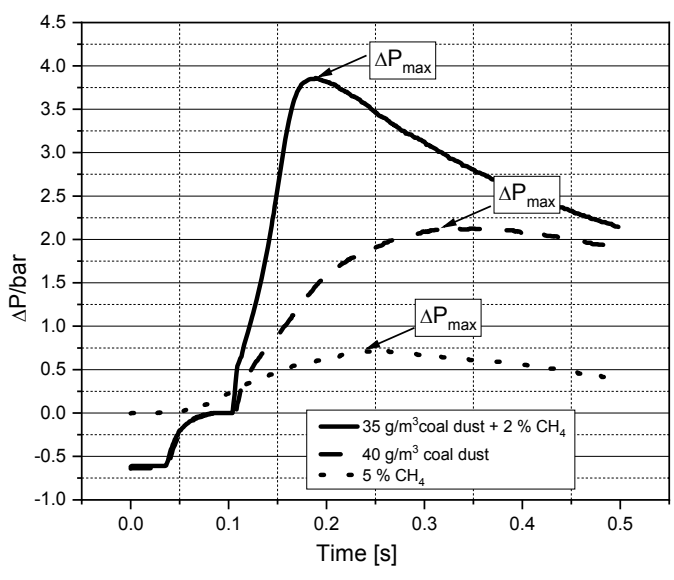

Many researchers investigated the behavior of hybrid mixtures explosions, especially of coal dust - methane - air mixtures in order to understand their properties. This kind of mixtures are often found in the mining industry, the co-presence of coal dust and methane in the underground being very dangerous. ${ }^{3}$

The effects of ignition energy on the explosive properties of coal dust have been studied by a number of researchers. ${ }^{4-6}$ In a paper from 2012, Yuan and the research group, ${ }^{4}$ used a $20 \mathrm{~L}$ apparatus for the determination of the minimum

\footnotetext{
* Corresponding author: maria.prodan@insemex.ro

${ }^{* *}$ Died in 2020
} 
explosive concentration for a given ignition energy. It was observed that the minimum ignition concentration is significantly reduced for coals with a higher volatile matter.

Bai and the research group ${ }^{5}$ have studied the overpressure field and the flame structure for hybrid mixtures methane air coal dust in a largescale system of $10 \mathrm{~m}^{3}$ explosion vessel using a horizontal cylinder with the internal diameter of $2.0 \mathrm{~m}$ and the length of $3.5 \mathrm{~m}$, with methane concentrations ranging from $4.5 \%$ to $8 \%$ and coal dust concentrations ranging from 25 to $70 \mathrm{~g} / \mathrm{m}^{3}$. They found that the explosion of methane/air mixture and methane/coal dust/air mixture could be divided into two stages: the pressure rise stage and the pressure decline stage. The flame propagated around in the form of a light blue fireball, the thickness of the flame was about $10 \mathrm{~mm}$ and the propagation speed of the flame fluctuated approximately at $2.5 \mathrm{~m} / \mathrm{s}$. The maximum overpressure of methane/coal dust/air mixture occured at the distance of $0.5 \mathrm{~m}$, and the maximum overpressure was 7.3 bar, respectively when the concentration of methane was $8 \%$ and the coal dust concentration was $25 \mathrm{~g} / \mathrm{m}^{3}$.

Li et al. in 2012, also investigated ${ }^{6}$ the behavior of methane coal dust air hybrid mixtures explosions with a $20 \mathrm{~L}$ apparatus and $10 \mathrm{~kJ}$ chemical ignitors for three coal dust sample ranging from 50 to $500 \mathrm{~g} / \mathrm{cm}^{3}$ and methane gas concentrations from 5 to $12,5 \%$. They reported that with the addition of methane to the air/coal dust mixtures, the explosion overpressure, pressure rise rate and the deflagration index increased significantly. Compared with coal particles, the ignition energy of methane is much smaller, the burning of methane gas would provide much more energy for coal particle pyrolysis and volatile gases ignition. They also found that the burning time of hybrid mixtures are greatly shortened with the addition of methane.

Similar findings were reported by $\mathrm{Xu}$ et al. 2012. ${ }^{7}$ They concluded that the pressure rise of explosion decreased as the diameter of the coal dust particles increased. Moreover, with agreement from previous studies, there was an optimum concentration at which the peak of explosion pressure was obtained (maximum explosion pressure). Finally, for coal dust concentrations of 200,300 and $400 \mathrm{~g} / \mathrm{m}^{3}$ mixed with methane of varying concentrations, it was observed that the explosion pressure and the maximum rate of overpressure increased as the concentration of methane increased up to the stoichiometric concentration.

The ignitability of coal dust or methane is enhanced by the presence of methane or coal dust. The presence of methane influences both the hybrid flame propagation velocity and the flame front temperature, both of which are also affected by the coal dust concentration. The flame propagation speed and maximum flame temperature through the mixture of coal dustmethane and air are higher than that of coal dust and other dust flame.,

The hybrid mixture methane/coal dust is the most dangerous hybrid mixture from underground coal mines. In order to occur, dust and hybrid explosions require four base components, namely: combustible, oxidizer, ignition source, dispersion of dust. Most of the explosion type events occur inside the process equipment such as mills, silos, cyclones, pipes. ${ }^{8}$ If a flammable gas is present in a dust cloud, the explosive character of the latter is enhanced. The minimum explosion concentrations and minimum ignition energies are greatly reduced and the maximum explosion pressure and maximum rate of pressure rise are higher. Thus, a flammable gas can bring within the explosion range a dust mixture that normally is under the minimum explosive concentration, even at a concentration of the gas that is lower that the explosion limit. ${ }^{9}$ Regarding the hybrid mixtures, Bartknecht ${ }^{10}$ studied the explosivity of cellulose dust - methane, butane and propane and observed that by adding a flammable gas, the explosion pressure is slightly increased compared to the accelerated increase of the rate of the pressure rise. Recently, Denkevits ${ }^{11,12}$ studied the explosion behavior of the graphite powder and its influence over the explosion severity of hybrid mixture of hydrogen-air and used chemical igniters and electrical spark to ignite the mixtures in a spherical explosion vessel with a volume of $20 \mathrm{~L}$. In the case of chemical igniters, the explosion overpressures obtained for the hybrid mixture hydrogen-airgraphite dust were much higher than those obtained for the hydrogen-air explosion. A more complex situation was observed for the maximum rate of pressure rise. ${ }^{12,13}$ A low quantity of hydrogen is acting like an additional ignition source, bringing an energy contribution to the system. Denkevits concluded that using reduced energy ignition source allows the identification of different evolution stages of the explosion by modifying the flammable gas concentration, stages 
that cannot be deduced by simply combining the behavior of components of the system.

In the present paper were studied the pressuretime histories of hybrid mixtures formed by coal dust, methane and air at different concentrations, at 1 bar initial pressure and normal temperature, using the standard $20 \mathrm{~L}$ spherical explosion vessel and $5 \mathrm{~kJ}$ chemical igniters or $10 \mathrm{~J}$ permanent sparks. From the early stages of the pressure-time history, when the pressure increase is equal to or less than the initial pressure, the normal burning velocities were evaluated and discussed.

\section{EXPERIMENTAL}

The explosion vessel is made from stainless steel, with a volume of $20 \mathrm{~L}$. The hybrid mixture flammable gas-aircombustible dust is made directly in the explosion vessel. The combustible dust is placed inside the dust container. For testing, the dust is dispersed into the sphere from a pressurized storage chamber via the outlet valve and a nozzle. The outlet valve is pneumatically opened and closed by means of an auxiliary piston. The valves for the compressed air are activated electrically. The experiments were made at the initial pressure of $1 \mathrm{~atm}$. Methane gas, $99.996 \%$ purity and coal from active coal mines in Jiu Valley were used for all experiments. The coal was collected from Lonea and Uricani Mine. In order to determine the explosive characteristics, the collected coal was subjected to processing operations, namely grinding, drying and mixing. The resulted powder, granulated at $63 \mu \mathrm{m}$, according to the specification in SR EN 14034$1,2,3^{14}$ was homogenized so that the quantity subjected to analysis was representative to the collected sample.

Hybrid mixtures of coal dust - air - methane, from 2 to $5 \%$ volume methane and from 75 to $250 \mathrm{~g} / \mathrm{m}^{3}$ coal dust, at initial pressure of 1 bar were studied. The available ignition sources were $5 \mathrm{~kJ}$ chemical igniters, which are normally used for igniting the dust clouds and $10 \mathrm{~J}$ permanent electric sparks (maximum voltage $15 \mathrm{kV}$ and maximum current $30 \mathrm{~mA}$ ) normally used for igniting gas mixtures.

\section{RESULTS AND DISCUSSION}

The experimental results, illustrating the synergetic effects of methane and coal dust on the hybrid's explosivity parameters, are given in Fig. 1.

The influence of the energy of the ignition source on the hybrid mixtures was studied for concentrations of both flammable substances near the lower explosive concentration. The results are given in Table 1 and Table 2.

When igniting the explosive mixture with $5 \mathrm{~kJ}$ chemical igniters, one can observe that for the hybrid mixtures formed by 75 to $250 \mathrm{~g} / \mathrm{m}^{3}$ coal dust and 2 to $4 \%$ vol. methane, the explosion pressure is slightly higher than for ignition with $10 \mathrm{~J}$ electrical spark, exemplified in Fig. 2.

For the hybrid mixture formed by coal dust from 75 to $250 \mathrm{~g} / \mathrm{m}^{3}$ and methane at lower explosion limit, $5 \%$ volume, the explosion pressures obtained at ignition with $10 \mathrm{~J}$ energy source equals and even overcome the explosion pressure obtained with the chemical igniter ignition, as can be seen in the Figure 3, one possible explanation being the inhibiting action of methane combustion products. The energy ignition source of $10 \mathrm{~J}$ and $5 \mathrm{~kJ}$ does not cause significant influence over value of the explosion pressure.

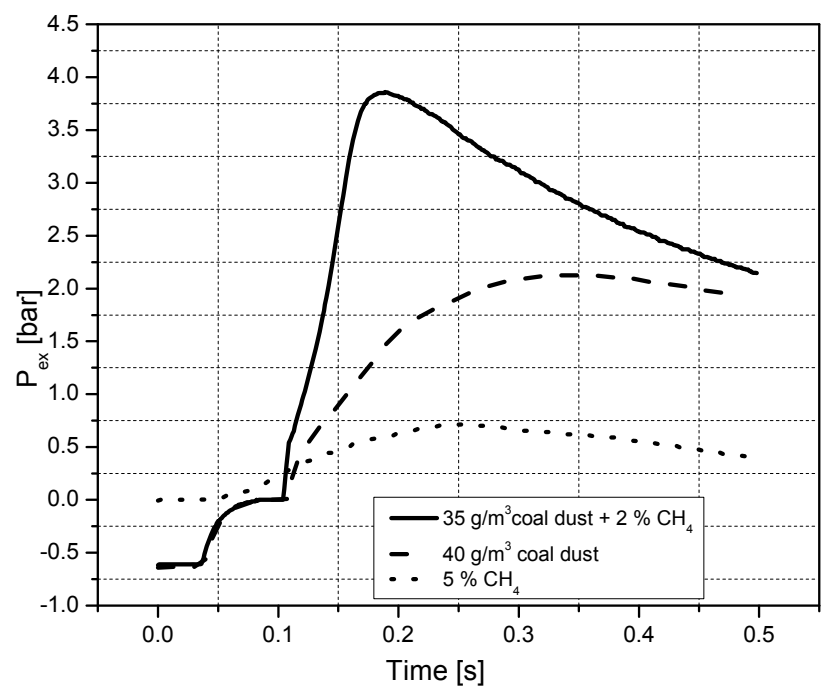

Fig. 1 - Explosion pressure evolution in time for coal dust - air, methane - air and coal dust - methane - hybrid mixture at $P_{0}=1 \mathrm{~atm}, \mathrm{~T}_{0}=298 \mathrm{~K}$. 
Table 1

Experimental data for hybrid mixtures explosion, ignited with $5 \mathrm{~kJ}$ ignition source energy

\begin{tabular}{l|c|c|c}
\hline $\begin{array}{c}\text { Coal dust } \\
\mathrm{g} / \mathrm{m}^{3}\end{array}$ & $\% \mathrm{CH}_{4}$ & $\begin{array}{c}\mathrm{P}_{\max } \\
\text { bar }\end{array}$ & $\begin{array}{c}(\mathrm{dP} / \mathrm{dt})_{\max } \\
\text { bar } / \mathrm{s}\end{array}$ \\
\hline 250 & \multirow{2}{*}{2} & 7.7 & 546 \\
125 & & 7.5 & 446 \\
75 & & 6.4 & 258 \\
\hline 250 & 3 & 7.6 & 624 \\
125 & & 7.5 & 516 \\
75 & & 7.0 & 468 \\
\hline 250 & 4 & 7.7 & 820 \\
125 & & 7.7 & 680 \\
75 & & 7.2 & 420 \\
\hline 250 & 5 & 7.6 & 892 \\
125 & & 7.3 & 796 \\
75 & & 6.7 & 734 \\
\hline
\end{tabular}

Table 2

Experimental data for hybrid mixtures explosion, ignited with $10 \mathrm{~J}$ ignition source energy

\begin{tabular}{l|c|c|c}
\hline $\begin{array}{c}\text { Coal dust } \\
\mathrm{g} / \mathrm{m}^{3}\end{array}$ & $\% \mathrm{CH}_{4}$ & $\begin{array}{c}\mathrm{P}_{\max } \\
\text { bar }\end{array}$ & $\begin{array}{c}(\mathrm{dP} / \mathrm{dt})_{\max } \\
\text { bar } / \mathrm{s}\end{array}$ \\
\hline 250 & \multirow{2}{*}{2} & 7.0 & 212 \\
125 & & 6.9 & 214 \\
75 & & 4.6 & 32 \\
\hline 250 & 3 & 7.3 & 504 \\
125 & & 7.4 & 314 \\
75 & & 6.1 & 132 \\
\hline 250 & 4 & 7.4 & 614 \\
125 & & 6.3 & 496 \\
75 & & 7.0 & 348 \\
\hline 250 & 5 & 7.8 & 1062 \\
125 & & 7.3 & 1036 \\
75 & & 6.7 & 776 \\
\hline
\end{tabular}

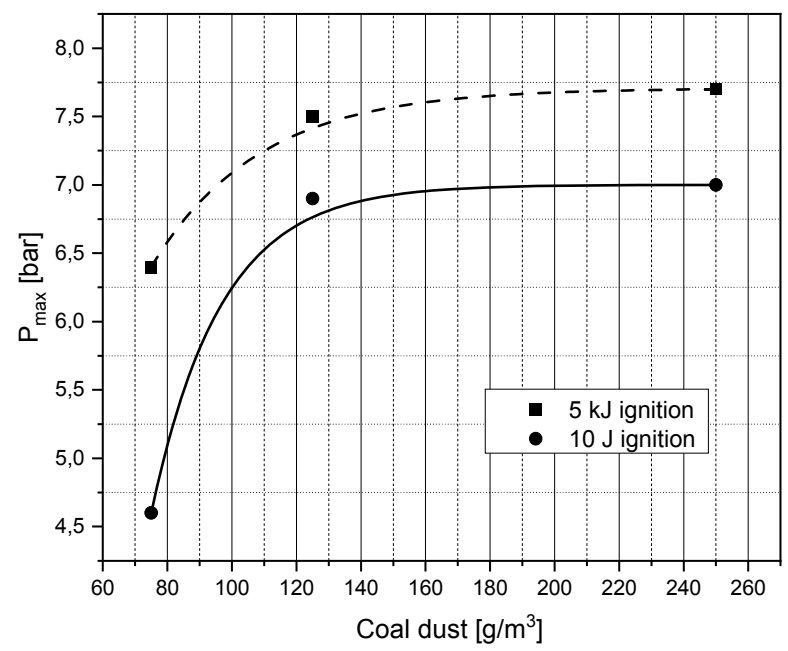

Fig. $2-\mathrm{P}_{\max }$ function of dust concentration for mixtures of coal dust and $2 \%$ methane.

The influence of methane gas concentration over the explosion pressure is given in the Figure 4 , where one can see that even though the value of explosion pressure is not greatly modified, the evolution in time is quite different, thereby with increasing the methane concentration, the severity of explosion is increased. 


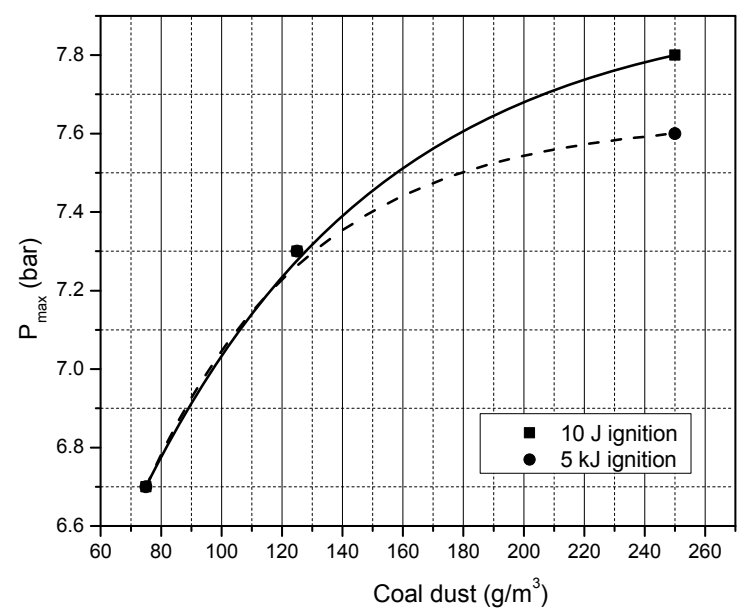

Fig. $3-\mathrm{P}_{\max }$ function of dust concentration for mixtures of coal dust and $5 \%$ methane.

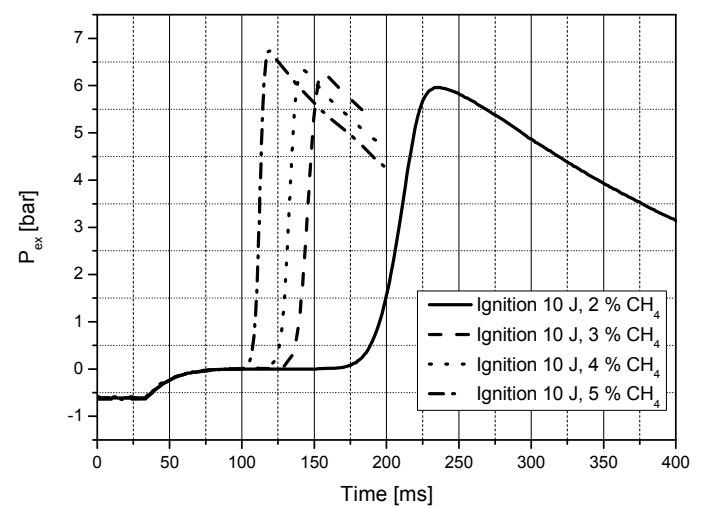

Fig. 4 - Explosion pressure evolution for hybrid mixtures for coal dust concentration of $125 \mathrm{~g} / \mathrm{m}^{3}$.

Regarding the evolution of maximum rate of pressure rise, $(\mathrm{dP} / \mathrm{dt})_{\max }$, this has a rising tendency for the studied domain with increasing the combustible substances concentration, using both ignition systems, an example can be seen in the Figure $5 \mathrm{a}, \mathrm{b}$.
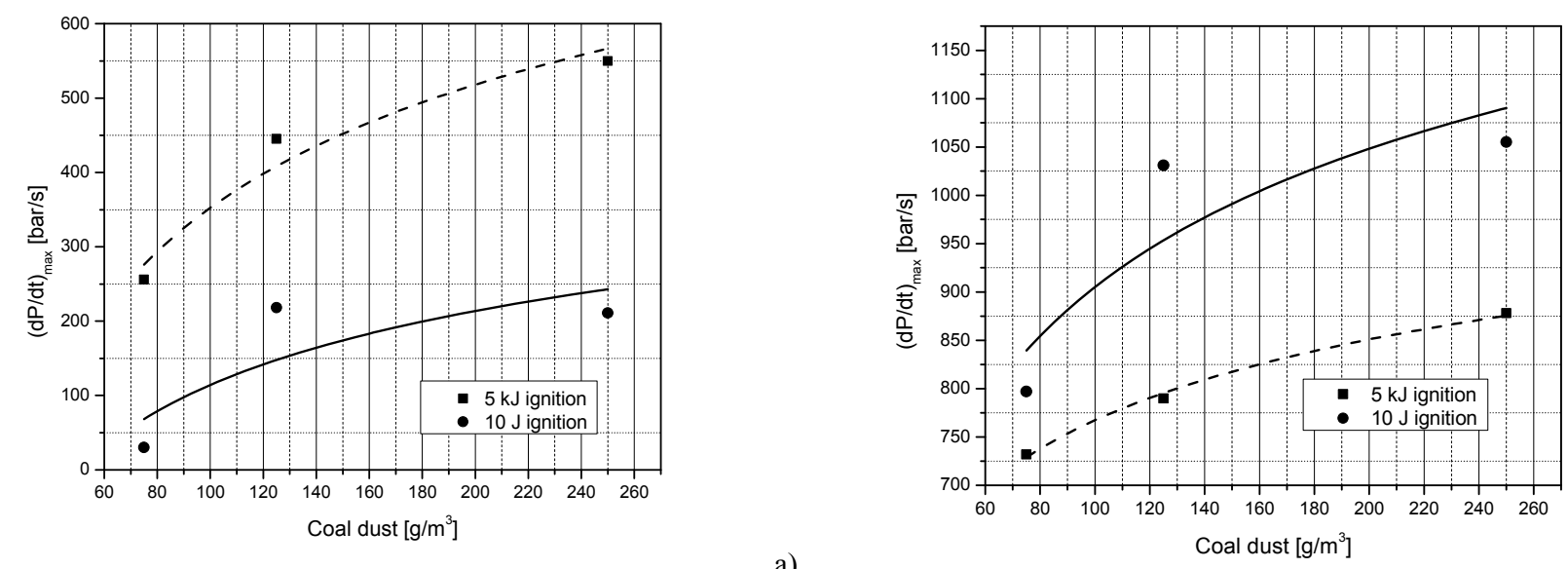

a)

Fig. 5 - Rate of pressure rise function of dust concertation for: a) $2 \% \mathrm{CH}_{4}$; b) $5 \% \mathrm{CH}_{4}$. 
One can observe though, that for $5 \mathrm{~kJ}$ chemical igniter the maximum rate of pressure rise has greater values than those obtained for the ignition with $10 \mathrm{~J}$ electric spark, except the hybrid mixture formed with $5 \%$ methane. For this mixture, where the flammable gas is at lower explosive limit, the value of maximum rate of pressure rise for the $10 \mathrm{~J}$ spark ignition overcomes the value obtained for the $5 \mathrm{~kJ}$ ignition. A possible explanation can be that the methane gas is first ignited from the spark, being in the explosive range, and its reaction products are generated before the ignition of the coal volatiles. In this way, the primary combustion of the methane is generating simultaneous precompression and heating of the coal particles, all these phenomena's being more intense than the ones produced by the chemical igniter.

In the case of the chemical igniter, the energy released is igniting both methane and coal dust, influencing each other by their reaction products that act as inhibitors of the reaction, the evolution of the explosion is thus slower. Moreover, the energetic value of the oxidation reaction at $5 \%$ volume greatly exceeds $5 \mathrm{~kJ}$ (every reacted methane mole generates $810 \mathrm{~kJ}$, respectively $5 \%$ of methane in $20 \mathrm{~L}$ generates $40,5 \mathrm{~kJ}$ ), causing an acceleration of the increase in pressure over time.

As can be seen, and like Denkevits reported for hydrogen, ${ }^{11,12}$ the methane concentration is acting like an addition ignition source, adding energy in the system.

The normal burning velocity of a flammable mixture at initial pressure $P_{0}$ is related to the coefficient $k$ of the cubic law of pressure rise derived by the assumption that in the early stage of explosion evolution the temperature of unburned gas is constant: ${ }^{15-19}$

$$
S_{u}=R_{c} \cdot\left(\frac{k_{3}}{\Delta P_{\max }}\right)^{1 / 3} \cdot\left(\frac{P_{0}}{P_{\max }}\right)^{2 / 3}
$$

where $R$ is the vessel radius, $k$ is the coefficient of the cubic law of pressure rise, $\Delta P_{\max }$ is the maximum pressure rise of the explosion and $P_{\max }=$ $P_{0}+\Delta P_{\max }$.

The coefficient $k_{3}$ is a dimensionless constant dependent of the nature and the state of the explosive mixture:

$$
\Delta P=k_{3} \cdot t^{3}
$$

The coefficient $k$ was determined for each experiment by a non-linear regression method of $\mathrm{p}(\mathrm{t})$ data, using an improved correlation with 3 adjustable parameters:

$$
\Delta P=a_{0}+k_{3} \cdot(t-\tau)^{3}
$$

where $a_{0}$ and $\tau$ are pressure and time correction respectively, meant to eliminate the signal shift of pressure transducer and any possible delay in signal recording. The computation was restricted to a pressure range of $\Delta \mathrm{P} \leq \mathrm{P}_{0}$.

The method described was applied successfully for a series of experimental data for determining the normal burning velocity of gaseous mixtures. ${ }^{15-}$ 19

In this work the method was applied for determining the normal burning velocity of hybrid mixtures. In order to verify the possibility of using this relation for this type of mixtures the experimental and computed data were compared with the literature data and with results obtained by using an equation (Eq. 4) proposed by van den Bulk $^{20}$ :

$$
S_{u}^{\prime}=\left(K_{\max } \cdot 0.9\right) / 4.836 \cdot\left[\left(\frac{P_{\max }}{P_{0}}\right)^{1 / 1.33}-1\right] \cdot P_{\max }
$$

The normal burning velocity variation for the analyzed systems is in good agreement with the variation of $(\mathrm{dP} / \mathrm{dt})_{\max }$ parameter and also it can be observed the situation for the lower energy source ignition, when methane is at lower explosive limit, when the ignition with the electrical spark is determining a higher burning velocity than the one obtained with the $5 \mathrm{~kJ}$ chemical igniter, as can be seen in the Figures 6 and 7.

The results obtained with the two theoretical models, respectively the one proposed by van den Bulk $^{20}$ and the one based on the assumption that in the early stage the unburned gases have constant temperature showed that the latter model can be used for the estimation of the normal burning velocity for hybrid mixtures also. The obtained results are in good agreement with the literature data. $^{21,22}$ The experimental and calculated burning velocities for the hybrid mixtures have similar values with those reported by other researchers. 


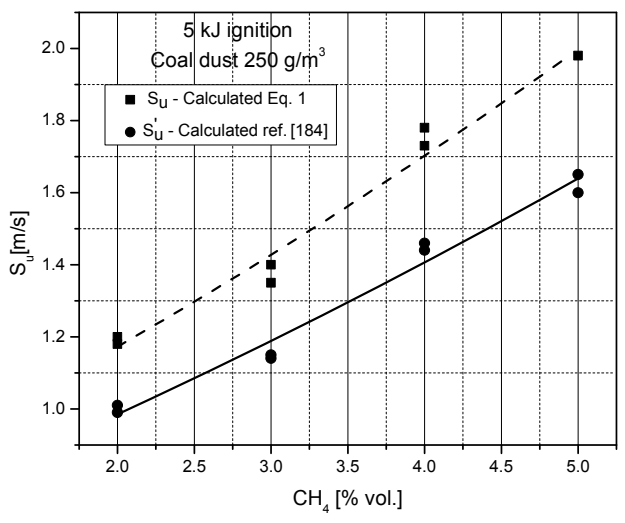

a)

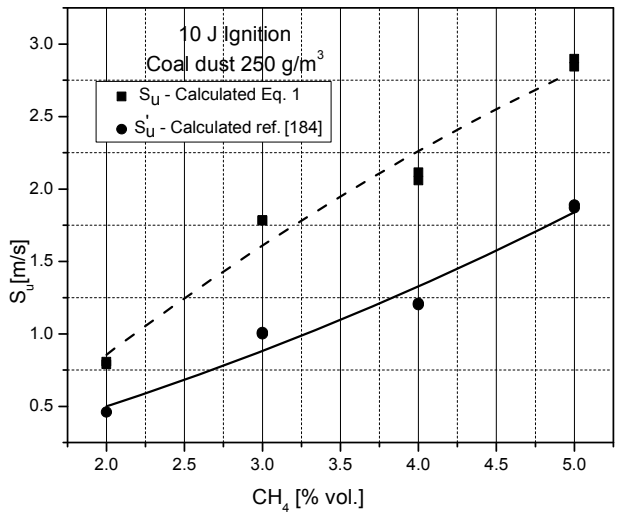

b)

Fig. 6 - Normal burning velocity, $S_{u}$, for hybrid mixtures function of methane concentration, evaluated with the Eq. 1 and 4 , for: a) 5 kJ ignition; b) $10 \mathrm{~J}$ ignition.

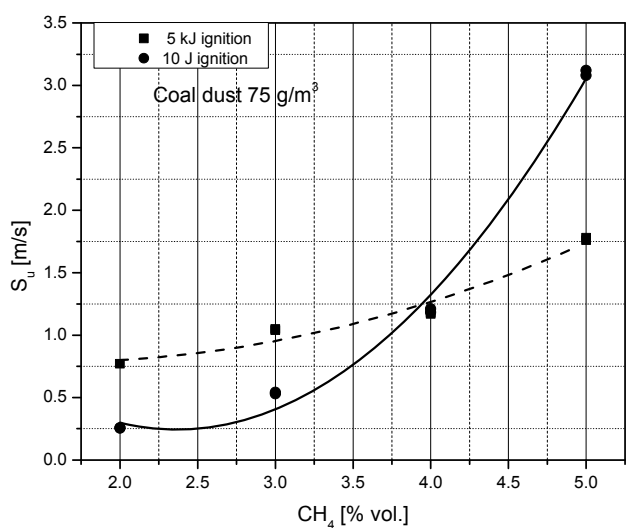

Fig. 7 - Normal burning velocity variation, $\mathrm{S}_{\mathrm{u}}$, function of methane concentration, calculated with Eq.1, for different energy ignition sources.

\section{CONCLUSIONS}

The experiments performed for the hybrid mixtures coal dust - air - methane, using ignition sources with different energy highlighted a less predictable behavior for the mixtures formed with the combustible gas at lower explosion limit, where the explosivity of the explosion was amplified for the lower energy source ignition, hence the need for reviewing and completing the existing standardized method for determining the parameters of explosive mixtures explosion. Another relevant aspect is given by the amplification of the explosion violence of the hybrid mixtures compared to the single component ones, which shows the importance to be given to technical and organizational measures that need to be taken in the industrial environments where are present both combustible dusts and flammable gases for avoiding the formation of explosive hybrid mixtures. The pressure-time history during deflagration of premixed fuel-air flammable mixtures in closed spherical vessels with central ignition has been widely used to determine the laminar burning velocities for gaseous mixtures. In several previous papers it has been proved that the analysis of early stages, relied on the cubic law of pressure rise, provides values of normal burning velocity in agreement with other reliable methods.

\section{REFERENCES}

1. R. Eckhoff, J. Loss Prevent. Proc. Ind., 2009, 22, 105116.

2. P. Amyotte, K. Mintz, M. Pegg and Y. Sun, Fuel, 1993, $72,5,671-679$.

3. Y. Liu, J. Sun and D. Chen, J. Loss Prevent. Proc. Ind., 2007, 20, 691-697. 
4. J. Yuan, W. Huang, B. Du, N. Kuai, Z. Li and J. Tan, Procedia Eng., 2012, 43, 343-347.

5. C. Bai, G. Gong, Q. Liu, Y. Chen and G. Niu, Safety Science, 2011, 49, 1349-1354.

6. Q. Li, B. Lin, H. Dai and S. Zhao, Powder technology, 2012, 229, 222-228.

7. H. Xu, X. Wang, R. Gu and H. Zhang, J. Eng. Gas Turbines Power, 2012, 134, 061401-1 - 061401-6, https://doi.org/10.1115/1.4005816.

8. T. Abbasi and S. Abbasi, J. of Haz. Mat., 2007, 140, 7-44.

9. P. Amyotte, J. Loss Prevent. Proc. Ind., 2005, 19, 161173.

10. W. Bartknecht, "Dust Explosions: Course, Prevention, Protection", Berlin: Springer, 1989,

11. A. Denkevits, Report on EFDA, Subtask TW4-TSSSEA5.2, May 2005.

12. A. Denkevits, J. Loss Prevent. Proc. Ind., 2007, 20, 698707.

13. G. Agreda, Universita Degli Studi Di Napoli Federico II, Napoli, 2010, 13-15.
14. SR EN 14034-1:3, EN Standard, 2011, 5.

15. D. Razus, D. Oancea and C. Movileanu, J. Loss Prevent. Proc. Ind., 2006, 19, 334-342.

16. D. Razus, D. Oancea, V. Brinzea, M. Mitu and C. Movileanu, Energy Conversion Management, 2010, 51, 2979-2984.

17. D. Razus, V. Brinzea, M. Mitu and D. Oancea, Energy and Fuels, 2010, 24, 1487-1494.

18. D. Oancea, D. Razus and I. Ionescu, Rev. Roum. Chim., 1994, 39, 1187-1192.

19. D. Oancea, D. Razus and I. Ionescu, Rev. Rom. Chim., 2000, 45, 319-330.

20. E. Van den Bulk, J. Loss Prevent. Proc. Ind., 2005, 18, $35-42$.

21. L. Qingzhao, L. Baiquan, D. Huaming and S. Zhao, Powder Technology, 2012, 229, 222-228.

22. A. Di Benedetto, A. Garcia-Agreda, O. Dufaud, I. Khalili, R. Sanchirico, N. Cuervo, L. Perrin and P. Russo, MCS - 7 Seventh Mediterranean Combustion Symposium Proceedings, 2011. 